\title{
Superior vena cava syndrome due to mediastinal adenomatous goitre
}

\author{
Hiroshi Katoh, Takumo Enomoto, Masahiko Watanabe
}

Department of Surgery, Kitasato University School of Medicine, Sagamihara, Japan

\section{Correspondence to} Dr Hiroshi Katoh, mohiro-kato@hotmail.co.jp

Accepted 23 May 2015

\section{DESCRIPTION}

A 60-year-old man presented with an 18-month history of deteriorating facial oedema and intermittent oedema of upper limbs. He had symptoms of headache, flush, dysphagia and coughs. He also noted hoarseness or dysphonia after standing for long periods. He had no other physical findings. MRI showed a superior to middle mediastinal mass derived from the right lobe of the thyroid, compressing the trachea to the left (figure 1, arrow heads). MR venography revealed severe stenosis of the right innominate vein indicating stasis of

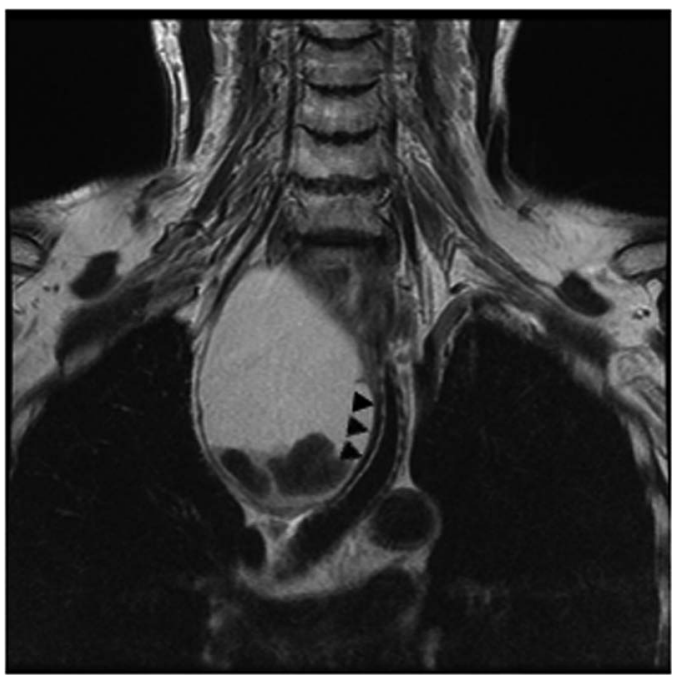

Figure 1 Plain MRI shows a superior to middle mediastinal mass expanding from right thyroid gland, compressing the trachea to the left (arrow heads). contrast medium, and remarkable collateral vessels along the vertebrae (figure $2 \mathrm{~A}$, arrows and arrow heads, respectively). The left innominate vein was also compressed by goitre (figure $2 \mathrm{~A}$, arrow on the left of the mass). The patient successfully underwent right lobectomy of the thyroid via a neck approach with collar incision. Pathological diagnosis was nodular hyperplasia including incidental micropapillary carcinoma. The stasis of veins was found entirely resolved in a 2-week follow-up visit (figure $2 \mathrm{~B}$, arrows)

Most superior vena cava (SVC) syndromes are caused by malignancies (eg, lymphoma and lung cancer). ${ }^{1}$ Although a goitre sometimes enlarges into supra mediastinum, SVC syndrome is a rare complication to be found. ${ }^{2}{ }^{3}$ However, a mediastinal large goitre may cause SVC syndrome, as in the case presented above. In this exceptional case, the goitre caused SVC syndrome even though the goitre was not detected in the physical examination, because of its limited presence in the mediastinum.

\section{Learning points}

- Mediastinal goitre may cause superior vena cava syndrome by compressing bilateral brachiocephalic veins.

- A goitre may not be detected by physical examination because of its limited presence in the mediastinum.

- Mediastinal goitre can be successfully removed through a cervical approach.
To cite: Katoh $\mathrm{H}$, Enomoto T, Watanabe M BMJ Case Rep Published online: [please include Day Month Year] doi:10.1136/ bcr-2015-210634
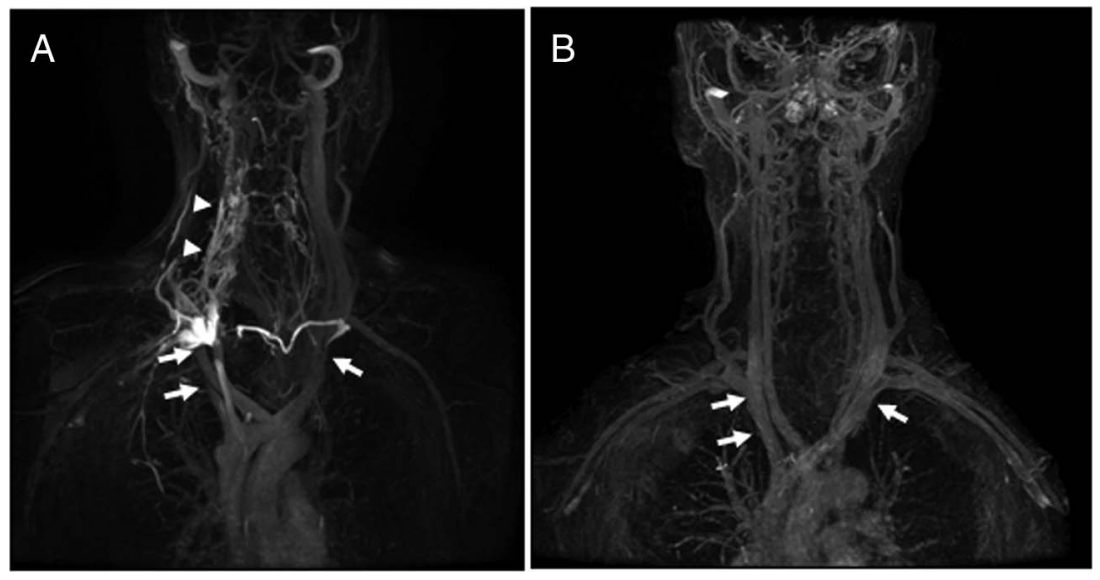

Figure 2 (A) MR venography shows severe stenosis of right innominate vein with stasis of contrast medium (arrows on the right side of the mass), and collateral vessels along vertebrae (arrow heads). Left innominate vein is also compressed (arrow on the left side of the mass). (B) MR venography in a 2-week follow-up visit indicates stenosis and stasis resolved entirely (arrows). 


\section{Images in...}

Contributors HK, TE and MW identified and managed the case.

Competing interests None declared.

Patient consent Obtained.

Provenance and peer review Not commissioned; externally peer reviewed.
2 Marcelino M, Nobre E, Conceicao J, et al. Superior vena cava syndrome and substernal goiter. Thyroid 2010;20:235-6.

3 Hedayati N, McHenry CR. The clinical presentation and operative management of nodular and diffuse substernal thyroid disease. Am Surg 2002;68:245-51; discussion $251-2$.

\section{REFERENCES}

1 Aasted A, Bertelsen S. Superior vena caval syndrome in benign mediastinal goitre. Acta Chir Scand 1981;147:405-8.

Copyright 2015 BMJ Publishing Group. All rights reserved. For permission to reuse any of this content visit http://group.bmj.com/group/rights-licensing/permissions.

BMJ Case Report Fellows may re-use this article for personal use and teaching without any further permission.

Become a Fellow of BMJ Case Reports today and you can:

- Submit as many cases as you like

- Enjoy fast sympathetic peer review and rapid publication of accepted articles

- Access all the published articles

- Re-use any of the published material for personal use and teaching without further permission

For information on Institutional Fellowships contact consortiasales@bmjgroup.com

Visit casereports.bmj.com for more articles like this and to become a Fellow 